\title{
Extraction of poly(3-hydroxybutyrate) from Spirulina LEB 18 for developing nanofibers
}

\author{
Michele Greque de Morais ${ }^{1}$, Christopher Stillings ${ }^{2}$, Roland Dersch², Markus Rudisile ${ }^{2}$, \\ Patricia Pranke $^{3}$, Jorge Alberto Vieira Costa ${ }^{4}$ and Joachim Wendorff ${ }^{2}$
}

\author{
${ }^{1}$ Laboratory of Microbiology and Biochemical, College of Chemistry and Food Engineering, \\ Universidade Federal do Rio Grande - FURG, Rio Grande, RS, Brazil \\ ${ }^{2}$ Department of Chemistry, Philipps-Universität Marburg, Marburg, Hessen, Germany \\ ${ }^{3}$ Hematology and Stem Cell Laboratory, Faculty of Pharmacy, \\ Universidade Federal do Rio Grande do Sul - UFRGS, Porto Alegre, RS, Brazil \\ ${ }^{4}$ Laboratory of Biochemical Engineering, College of Chemistry and Food Engineering, \\ Universidade Federal do Rio Grande - FURG, Rio Grande, RS, Brazil \\ *wendorff@staff.uni-marburg.de; michele.morais@pq.cnpq.br
}

\begin{abstract}
The objective of this study was to extract poly(3-hydroxybutyrate) (PHB) from the microalgal biomass of Spirulina LEB 18 for the development of nanofibers by electrospinning method. Different extraction methods were tested. The maximum yield obtained was $30.1 \pm 2 \%$. It was possible to produce nanofibers with diameters between $826 \pm 188 \mathrm{~nm}$ and $1,675 \pm 194 \mathrm{~nm}$. An increase in the nanofiber diameter occurred when a flow rate of $4.8 \mu \mathrm{L} \mathrm{min}^{-1}$ and a capillary diameter of $0.90 \mathrm{~mm}$ were used. The nanofibers produced had up to $34.4 \%$ of biomass additives, i.e., non-PHB materials. This can be advantageous, because it enables the conservation of microalgal biomass compounds with bioactive functions.
\end{abstract}

Keywords: biomass, electrospinning, nanofibers, PHB, Spirulina.

\section{Introduction}

Microalgae are photosynthetic organisms with relatively simple requirements for growth when compared with other biomass sources. The composition and rates of photosynthesis and growth of these microorganisms are highly dependent on culture conditions; if these conditions are manipulated, metabolites of interest can be produced ${ }^{[1]}$. Polyhydroxyalkanoates (PHAs) are biopolymers that are produced and accumulated by microorganisms as energy reserves, and they can be synthesized by microalgae. One PHA that has attracted international scientific, technological and industrial interest is poly(3-hydroxybutyrate) (PHB), due to the fact that it is thermoplastic, biodegradable and biocompatible with cells and tissues ${ }^{[2,3]}$.

Several PHA extraction processes may be used; however, it is important to develop efficient methods that lower production costs ${ }^{[3]}$. The processes that are most commonly used are based on extraction with trichloromethane (sometimes pre-treated with acetone), followed by precipitation with diethyl ether or methano ${ }^{[3,4]}$. Sodium hypochlorite, methylene chloride, dichloroethane and propylene carbonate are also used in extraction processes ${ }^{[3]}$.

Due to its biodegradability and biocompatibility with cells and tissues, PHB has a strong potential for use in the development of nano or microfibers in the fields of food and medicine. Sensors can be placed in packaging to detect pathogens in foods that change the color of the packaging in order to alert the consumer if there is a problem, or to release preservatives if the food begins to deteriorate ${ }^{[5]}$.

Nanofiber technology can be used to incorporate bioactive additives such as probiotics, prebiotics, antioxidants or vitamins in packaging. These additives are released at the time of consumption. Some functional components are not compatible with food: they may produce unwanted flavors and odors, or modify the texture of food, so it is better to incorporate them in the packaging and release them at the time of consumption, rather than adding them to the food itself during processing ${ }^{[5]}$.

Electrospinning is carried out by applying high voltage to a polymer solution in a process that results in nanofiber formation and lengthening due to electrostatic repulsion. The polymer solution is fed at a constant flow rated through a capillary charged with a high tension. When the electric field attains enough energy to overcome surface tension at the tip of the capillary a 'Taylor Cone' forms and the nanofiber are deposited in a collector where the solvent evaporates and the nanofibers collect ${ }^{[6-8]}$.

The objective of this study was to extract poly(3-hydroxybutyrate) from the microalgal biomass of Spirulina LEB 18 for the development of nanofibers.

\section{Materials and Methods}

\subsection{Production of the Spirulina LEB 18 (Arthrospira) microalgal biomass}

The microalga used in this study was Spirulina LEB 18, which was isolated from the Mangueira Lagoon..$^{[9]}$ Zarrouk culture medium at $20 \%(\mathrm{v} / \mathrm{v})^{[10]}$ supplemented with Mangueira Lagoon water was used during the microalgal development. 
The cultures were prepared at a pilot plant to produce Spirulina LEB 18, on the edge of Mangueira Lagoon (33 $30^{\prime} 13^{\prime \prime} \mathrm{S}$ and $\left.53^{\circ} 08^{\prime} 59^{\prime \prime} \mathrm{W}\right)$. The unit consisted of three $10,000 \mathrm{~L}$ raceway-type bioreactors and one 1,000 L raceway-type tank. The reactors were coated with fiberglass and covered with transparent plastic film. The cultures were agitated by rotating blades at $18 \mathrm{rpm}^{[11]}$.

Every $72 \mathrm{~h}$, the microalgal biomass was harvested with the aid of a $200 \mu \mathrm{m}$ filter. The filtrate was returned to the tanks, and nutrients were used until they were exhausted. The filtrate was concentrated in a hydraulic press, and the biomass was extruded. After extrusion, the biomass was dried at $50{ }^{\circ} \mathrm{C}$ for 5 hours in a tray dryer, vacuum packed and stored ${ }^{[11]}$. Extraction tests were carried out using this biomass.

\subsection{Extraction of PHB using 4\% sodium hypochlorite}

Sodium hypochlorite $10 \%(\mathrm{v} / \mathrm{v})$ was diluted and the final concentration was $4 \%(\mathrm{v} / \mathrm{v})$. The microalgal biomass was mixed with $4 \%$ sodium hypochlorite and agitated for $20 \mathrm{~min}$, and then centrifuged to separate the dead cells. The process was repeated and it was then rinsed twice with distilled water, followed by centrifugation and rinsing with acetone to facilitate drying. The PHB was stored at $25^{\circ} \mathrm{C}$ for 72 hours for evaporation of water ${ }^{[4]}$ (Sample PHB1).

\subsection{Extraction of PHB using trichloromethane}

PHB was extracted from the dry microalgal biomass using trichloromethane at $65^{\circ} \mathrm{C}$ for $4 \mathrm{~h}$. The biomass containing trichloromethane was filtered to remove ruptured cells. The trichloromethane was evaporated and PHB was precipitated with methanol. PHB was kept at $25{ }^{\circ} \mathrm{C}$ for 72 hours for evaporation of water (Sample PHB2).

\subsection{Extraction of PHB with trichloromethane using pre- treatment with $4 \%$ sodium hypochlorite}

To remove the pigments, microalgal biomass was pre-treated with $10 \%$ sodium hypochlorite $(\mathrm{v} / \mathrm{v})$ that was diluted in water until a final concentration of $4 \%(\mathrm{v} / \mathrm{v})$ was achieved. The microalgal biomass was mixed with $4 \%$ sodium hypochlorite and agitated for $20 \mathrm{~min}$, and then centrifuged to separate the dead cells. The process was repeated and it was then rinsed twice with distilled water, followed by centrifugation and rinsing with acetone to facilitate drying. PHB was kept at $25^{\circ} \mathrm{C}$ for 72 hours for evaporation of water ${ }^{[4]}$.

Afterwards, extraction with trichloromethane at $65{ }^{\circ} \mathrm{C}$ for 4 hours was carried out, followed by filtration to remove ruptured cells. The trichloromethane was evaporated and the PHB precipitated with methanol. Methanol and PHB were centrifuged for separation and PHB was maintained at $25^{\circ} \mathrm{C}$ for 72 hours for evaporation of water (Sample PHB3).

\subsection{Extraction of PHB with trichloromethane using pre-treatment with $10 \%$ sodium hypochlorite}

Sodium hypochlorite at $10 \%(\mathrm{v} / \mathrm{v})$ and trichloromethane were added to the microalgal biomass, which was agitated for $150 \mathrm{~min}$. After this, the mixture was separated into three phases using a funnel. The upper phase contained sodium hypochlorite, the central phase contained the ruptured cells and the lower phase contained trichloromethane and $\mathrm{PHB}^{[4]}$. The trichloromethane was evaporated and the PHB was precipitated with methanol. Methanol and PHB were centrifuged for separation. PHB was maintained at $25^{\circ} \mathrm{C}$ for 72 hours for evaporation of water (Sample PHB4).

\subsection{Preparation of solutions for electrospinning}

Electrospinning tests were carried out with PHBs that were obtained from four extractions, using trichloromethane as a solvent. In the tests using PHB1, the samples were tested at concentrations of 20, 25, 30, 35, 40, 50 and $60 \%(\mathrm{w} / \mathrm{v})$.

PHB2 was tested at concentrations of 25, 35 and $45 \%(\mathrm{w} / \mathrm{v})$. This sample was also tested with the addition of Spirulina LEB 18 biomass. The concentrations of PHB2 and biomass were: $20 \%$ PHB2 and 5\% biomass; $20 \%$ PHB2 and $10 \%$ biomass; $25 \%$ PHB2 and $5 \%$ biomass; $25 \%$ PHB2 and $10 \%$ biomass; $30 \%$ PHB2 and $10 \%$ biomass; $30 \%$ PHB2 and $20 \%$ biomass; $35 \%$ PHB2 and $10 \%$ biomass; $35 \%$ PHB2 and $15 \%$ biomass; $40 \%$ PHB2 and $10 \%$ biomass. All concentrations are in percentages $(w / v)$.

In the process using PHB3, the solutions were prepared at concentrations of $15,20,25$ and $30 \%(w / v)$. Solutions of PHB3 with the addition of Spirulina LEB 18 microalgal biomass were also tested. In these tests, 7\% (w/v) PHB3 was used with $7 \%(\mathrm{w} / \mathrm{v})$ biomass; $20 \%(\mathrm{w} / \mathrm{v})$ PHB3 with $5 \%(\mathrm{w} / \mathrm{v})$ biomass and 25\% (w/v) PHB3 containing 5\% (w/v) biomass.

In the tests with PHB4, electrospinning was carried out using concentrations of 15, 20 and $30 \%(w / v)$.

All the samples were homogenized in a magnetic agitator at $21{ }^{\circ} \mathrm{C}$. The yield of PHB obtained through the different extraction methods was evaluated by analysis of variance (ANOVA) and Tukey's test to compare the means, at a $95 \%(\mathrm{p} \leq 0.05)$ significance level.

\subsection{Electrospinning process}

In the electrospinning process, solutions were injected through a capillary with a diameter $\left(D_{c}\right)$ of 0.45 to $1.10 \mathrm{~mm}$. The distance between the end of the capillary and the collector $\left(\mathrm{D}_{\text {cc }}\right)$ was $150 \mathrm{~mm}$. The electric potential (EP) that was applied ranged from 15.4 to $31.3 \mathrm{kV}$. The solution flow rate (FR) was between 0.7 and $5.8 \mu \mathrm{L} \mathrm{min}{ }^{-1}$, which was controlled by a pump connected to the pipette. All experiments were carried out at $21^{\circ} \mathrm{C}$.

\subsection{Characterization of fibers}

A scanning electron microscope (SEM) (Jeol JSM-7500F, Germany) was used to observe the morphology of the fibers. The mean fiber diameter was determined by measuring 30 different points on the SEM images. The apparent viscosity of all samples was determined using a viscometer (Haake PK100, Germany). The apparent viscosity and fiber diameter were assessed by analysis of variance (ANOVA) and Tukey's test for comparison of means at a significance level of $95 \%(\mathrm{p} \leq 0.05)$.

The molar mass of polymers was determined by gel permeation chromatography (GPC) using a high resolution HPLC chromatograph (Knauer SL1000, Germany) equipped with a Polymer Standard Services column, and two detectors 
(detector 1: Knauer V K2500 and detector 2: Knauer RI). Hexaisofluorpropanol (Aldrich, Germany) was used with solvent in the mobile phase at a flow rate of $0.5 \mathrm{~mL} \mathrm{~min}^{-1}$. The system was maintained at $23^{\circ} \mathrm{C}$ and $100 \mu \mathrm{L}$ of solution was injected. Polystyrene (Aldrich, Germany) was used as the standard molar mass. The molar mass of the samples was determined with the aid of a standard curve.

The thermal degradation and degree of impurity of the polymers were measured using a thermogravimetric analyzer (TGA/SDTA $851^{\mathrm{e}}$, Mettler, Germany). Approximately $10 \mathrm{mg}$ of the sample was heated from 25 to $800^{\circ} \mathrm{C}$ to $10^{\circ} \mathrm{C} \mathrm{min}^{-1}$ in a nitrogen atmosphere. The temperatures of onset and maximum degradation were determined by first derivative curves of TGA and the degree of impurities characterized by the amount of sample remaining at the end of the process.

Differential scanning calorimetry (DSC) was carried out to determine the degree of crystallinity $\left(\chi_{C}\right)$ of the polymers, by using crystallization enthalpy $\left(\Delta \mathrm{H}_{c}\right)$ and fusion enthalpy using a calorimeter (DSC $821^{\mathrm{e}}$, Germany) in a nitrogen atmosphere. Samples weighing approximately $10 \mathrm{mg}$ were sealed in aluminum with heating and cooling between 25 and $200{ }^{\circ} \mathrm{C}$ to $10{ }^{\circ} \mathrm{C} \mathrm{min}-1$. The degree of crystallinity was obtained by fusion enthalpy and crystallization enthalpy, considering that the fusion enthalpy for $100 \%$ crystalline PHB is $142 \mathrm{~J} \mathrm{~g}^{-1[12]}$.

\section{Results and Discussion}

\subsection{Extraction yield}

The PHB1 extraction method (4\% sodium hypochlorite $\mathrm{w} / \mathrm{v})$ resulted in a greater $(\mathrm{p}=0.0002)$ yield of polymer $(30.1 \pm 2 \%)$. There was no significant difference $(p>0.85)$ between the other extraction methods regarding the concentration of PHB obtained from the microalgal biomass, with values between $1.02 \% \pm 0.20$ and $1.71 \pm 0.10 \%$ (Table 1 ).

According to Panda et al., ${ }^{[13]}$ the manipulation of culture conditions of the Synechocystis sp. PCC 6803 microalga increased the $\mathrm{PHB}$ content by six times. The largest accumulation of PHB in microalgae was $55 \%$, which was observed in Synechococcus sp. MA19 when cultivated with a limited concentration of phosphate ${ }^{[14]}$. In this study, when Spirulina LEB 18 was cultivated, there was no imbalance, nor optimization of culture conditions to induce the production of polymers. However, the concentration obtained was between $30.1 \pm 2 \%$ and $1.02 \pm 0.20 \%$, which shows that this microalga has a potential for PHB synthesis.

Extractions with sodium hypochlorite (samples PHB1, PHB3 and PHB4) produced yellow polymers, while the extraction with trichloromethane (PHB2), produced a green polymer. PHB granules are located near the thylakoid membrane, which is the site of photosynthesis energy generation. The proximity between the PHB granules and thylakoid membrane hinders the separation of PHB and photosynthetic pigments, especially chlorophyll $a .^{[1]}$ Thus, the extraction of PHB from microalgae requires certain adjustments to obtain polymer without pigments. However, the extraction process used in PHB2 can help to preserve the microalga's active components, which is extremely useful for the medical and food industries.

\subsection{Degradation and melting properties}

The PHB2 extraction had a maximum initial degradation temperature of $240.9^{\circ} \mathrm{C}$. The initial degradation temperatures of samples obtained from extractions PHB1, PHB3 and PHB4 were between 162.1 and $166.6^{\circ} \mathrm{C}$ (Table 1). The samples had a maximum degradation temperature of between 453.7 and $484.7^{\circ} \mathrm{C}$. Sombatmankhong et al. ${ }^{[15]}$ obtained a degradation temperature of $263.5^{\circ} \mathrm{C}$ for PHB.

The PHB samples had a melting point between 171.9 and $126.3^{\circ} \mathrm{C}$, and the maximum melting point obtained was for the polymer extracted with trichloromethane. Sombatmankhong et al. ${ }^{[15]}$ obtained a melting temperature of $172.6^{\circ} \mathrm{C}$ for samples of commercial PHB. In nanofibers developed with PHB, Kim et al. ${ }^{[16]}$ obtained a melting temperature of $165^{\circ} \mathrm{C}$.

The maximum degree of crystallinity was found in sample PHB2 (1.21\%). However, this value is lower than that quoted in the literature for PHB, which is between 60 and $80 \%$ (Table 1). Therefore, the polymers that were obtained in this study should be considered to be amorphous. Crystalline polymers have better chemical resistance and are more brittle.

\subsection{Molar mass}

The maximum molar mass values obtained were $4.81,10^{6} \mathrm{Da}$ (PHB2), 4.36,106 Da (PHB1), followed by $3.85,10^{6} \mathrm{Da}$ (PHB3) and $1.59,10^{5} \mathrm{Da}$ (PHB4). During extraction of PHB from Alcaligenes eutrophus, with $30 \%$ hypochlorite and trichloromethane $(1: 1)$ for $90 \mathrm{~min}$, Hahn et al., ${ }^{[4]}$ obtained a polymer with a molar mass of $3 \cdot 0,10^{5} \mathrm{Da}$. In the extraction using trichloromethane, the molar mass of PHB was 5.3,10 ${ }^{5} \mathrm{Da}^{[4]}$ When Choi and Lee ${ }^{[3]}$ extracted PHB from Escherichia coli with trichloromethane, $\mathrm{NaOH}$ and $\mathrm{KOH}$ they obtained a molar mass of $2.2,10^{6}, 1.9,10^{6}$ and $2.0,10^{6} \mathrm{Da}$, respectively. The molar mass varied according to the microorganism used to extract the polymer, as well as with the conditions that the organism was exposed to and the extraction method used to recover PHB.

The degradation caused in the PHB2 molecules was insignificant, but the reagents used in the PHB1 extraction

Table 1. Method of extraction used to obtain PHB, yield $(\gamma)$ obtained in the extractions and responses of initial temperature of degradation $\left(\mathrm{TG}_{\mathrm{o}}\right)$, final temperature of degradation $\left(\mathrm{TG}_{\mathrm{f}}\right)$, impurities (IP), melting temperature $\left(\mathrm{T}_{\mathrm{m}}\right)$ degree of crystallinity $\left(\chi_{\mathrm{c}}\right)$, mean molar mass $\left(\mathrm{M}_{\mathrm{w}}\right)$ of polymers used in the development of fibers (mean \pm standard deviation).

\begin{tabular}{cccccccc}
\hline $\begin{array}{c}\text { Extraction } \\
\text { Condition }\end{array}$ & $\gamma(\mathbf{\%})$ & $\mathbf{T G}_{\mathbf{0}}\left({ }^{\circ} \mathbf{C}\right)$ & $\mathbf{T G}_{\mathbf{f}}\left({ }^{\circ} \mathbf{C}\right)$ & $\mathbf{I P}(\mathbf{\%})$ & $\left.\mathbf{T}_{\mathbf{m}}{ }^{\circ} \mathbf{C}\right)$ & $\boldsymbol{\chi}_{\mathbf{c}}(\mathbf{\%})$ & $\mathbf{M}_{\mathbf{w}}(\mathbf{D a})$ \\
\hline PHB1 & $30.1 \pm 2.0^{\mathrm{b}}$ & 162.1 & 464.0 & 31.3 & 126.4 & 0.31 & $4.36,10^{6}$ \\
PHB2 & $1.71 \pm 0.1^{\mathrm{a}}$ & 240.9 & 453.7 & 34.4 & 171.9 & 1.21 & $4.81,10^{6}$ \\
PHB3 & $1.54 \pm 0.5^{\mathrm{a}}$ & 166.6 & 484.7 & 26.8 & 127.5 & 0.17 & $3.85,10^{6}$ \\
PHB4 & $1.02 \pm 0.2^{\mathrm{a}}$ & 163.5 & 461.4 & 30.5 & 126.3 & 0.23 & $1.59,10^{5}$ \\
\hline
\end{tabular}

Same letters in the same column indicate no significant differences between experiments $(\mathrm{p}>0.05)$. 
drastically decreased the molar mass ${ }^{[4]}$. These reagents caused further deterioration in cellular components due to the denaturation of nucleic acids and inactivation of enzymes. In this study, the method PHB4 resulted in PHB molecules with a lower molar mass.

\subsection{Biomass impurities}

The TGA analysis showed that the PHB2 extraction had the maximum amount of non-PHB materials (34.4\%), and PHB3 had the lowest concentration of these materials (26.8\%). The samples obtained by extraction methods PHB1 and PHB3 had non-PHB concentrations of 31.3 and $30.5 \%$, respectively.

Clinical studies suggest that compounds in Spirulina biomass have therapeutic functions, such as polysaccharides with an anti-inflammatory effect, ${ }^{[17]}$ fatty acids with antibacterial and antifungal properties ${ }^{[18]}$ and Calcium Spirulan, which has been reported to inhibit lung metastasis in humans, by preventing attachment and proliferation of tumor cells. ${ }^{[19]}$ In an attempt to keep the active properties of microalgal biomass, purification processes were not carried out after the extractions. This led to materials other than PHB in the sample, which were identified as impurities.

\subsection{Nanofibers obtained via electrospinning}

PHB2 and PHB3 presented uniform nanofibers, without droplets and stable electrospinning maintaining the continuity of the process (Figure 1 and Figure 2). Thus, these samples were selected for the development of nanofibers, incorporating the microalgal biomass of Spirulina LEB 18.

The samples of PHB1 and PHB4 not presented fibers. When the electrospinning test was carried out with lower concentration (20\% PHB1 and $15 \%$ PHB4) there was no fiber formation, only drops (Table 2).

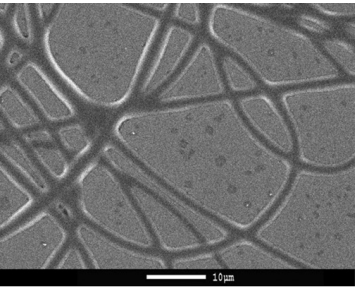

(a)

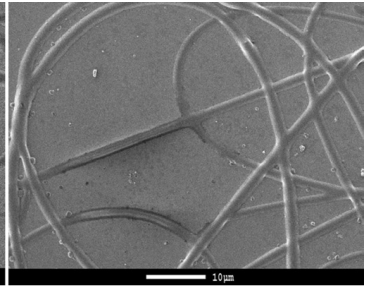

(b)
Figure 1. Electron microscopy images (SEM) magnified 2,000 times, of nanofibers developed with solutions containing $35 \%$ PHB2 (a); and 25\% PHB2 and 5\% Spirulina LEB 18 microalgal biomass (b).

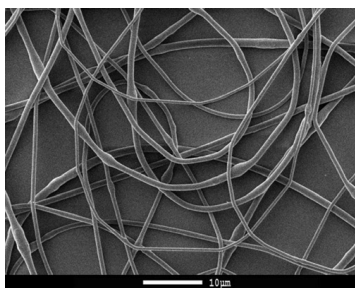

(a)

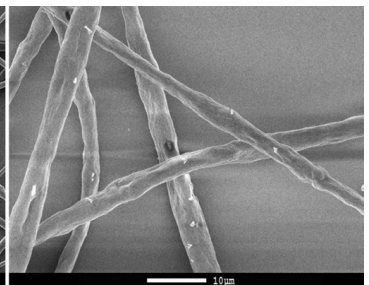

(b)
Figure 2. Electron microscopy images (SEM) magnified by 2,000 times, of nanofibers developed with solutions containing 30\% PHB3 (a); and 25\% PHB3 and 5\% Spirulina LEB 18 microalgal biomass (b).
In higher concentration ( 25 to $60 \%$ PHB1) solutions had fibers containing droplets and electrospinning was hindered by the obstruction of the capillary during the process. In the experiments containing 30\% PHB4 was formed nanofibers with too much droplets, independent the condition tested in the electrospinning (Table 2).

The concentrations of the solutions of PHB2 and PHB3 that presented prospects of forming nanofibers were tested in different conditions of the electrospinning process (Table 3). The electrospinning conditions that had the best nanofiber characteristics during the process are presented in Table 3 asteriscked.

In selecting the best condition to form uniform nanofibers, the parameters were varied according to the need that was observed by the analyst. For example, in the sample containing $35 \%$ PHB2 was initially tested a random electric potential condition, feed flow rate, distance to the collector and the capillary and diameter of the capillary. Based on the results obtained in this experiment 1 , it was observed that the increased electric potential could improve the characteristics of the nanofiber obtained. Thus, the electric potential was increased from $18.1 \mathrm{kV}$ to $24.3 \mathrm{kV}$ in the experiment 2 . The changes made between the experiments are highlighted in Table 3 with the variation of colors. Therefore, several tests have been performed and the end of the experiments, microscopic observation of nanofibers showed that the best condition was $24.3 \mathrm{kV}$ and $2 \mu \mathrm{min}^{-1}$, distance from the capillary to the collector of $15 \mathrm{~cm}$ and a capillary diameter of $0.45 \mathrm{~mm}$. All experiments were conducted in this way (Table 3).

The smallest diameter of nanofibers was $826 \pm 188 \mathrm{~nm}$, obtained when a solution containing 30\% PHB3 was used (Table 4). Suwantong et al., ${ }^{[20]}$ obtained nanofibers prepared with $14 \%$ PHB in trichloromethane with a diameter of $3,700 \pm 1,700 \mathrm{~nm}$. Solutions of $20 \%$ poly(3-hydroxybutyrate-co-valerate) in trichloromethane, had fibers with diameters between 1,000 and $4,000 \mathrm{~nm}^{[21]}$.

The nanofibers developed in this study had smaller diameters when compared to those of the authors previously mentioned. Smaller diameters cause the nanofibers to pack closer together with less distance between them. In the development of food packaging such a characteristic is favorable because it blocks oxygen, carbon dioxide and humidity. In tissue engineering, the small diameter increases the contact area, which stimulates adhesion, migration and proliferation of cells in nanofibers ${ }^{[21]}$.

There was no significant difference regarding the diameter of the fibers for the other conditions tested. However, a faster flow rate of the solution and a larger capillary orifice produced an increase in the diameter of the fiber. In the sample containing $30 \%$ PHB3, which had a smaller nanofiber diameter $(826 \pm 188 \mathrm{~nm})$, the flow rate was $2 \mu \mathrm{L} \mathrm{min}^{-1}$ and the capillary orifice was $0.45 \mathrm{~mm}$. However, the maximum diameter $(1,675 \pm 194 \mathrm{~nm})$ was obtained with $25 \%$ PHB3 and $5 \%$ microalgal biomass, using a $0.90 \mathrm{~mm}$ capillary diameter and a flow rate of $4.8 \mu \mathrm{L} \mathrm{min}{ }^{-1}$ (Figure 1 and Figure 2).

The flow rate of the solution influences the speed of the jet and the rate of transference of nanofibers to the collector. Megelski et al. ${ }^{[22]}$ observed that the diameter of nanofibers increases proportionally with the flow rate of the solution. A small inner diameter of the capillary reduces the diameter 


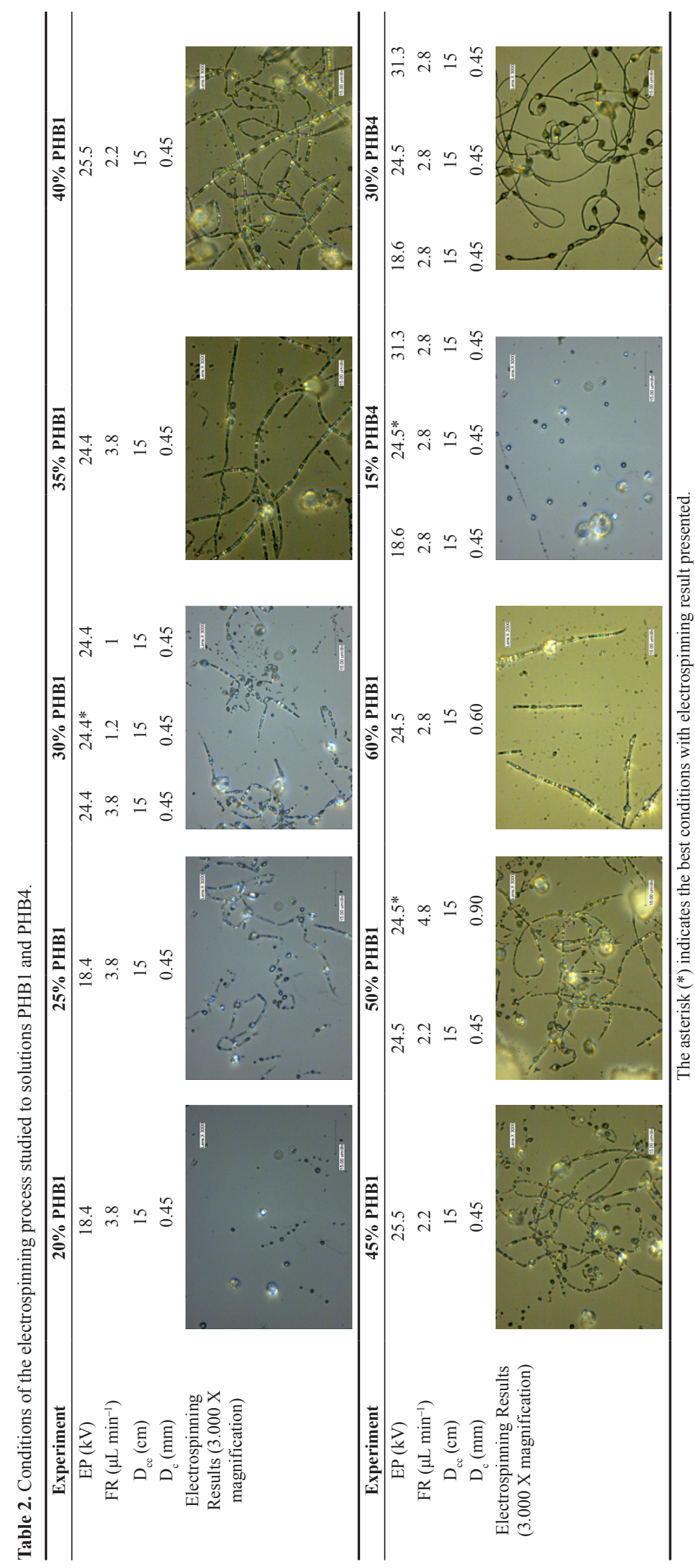


Morais, M. G., Stillings, C., Dersch, R., Rudisile, M., Pranke, P., Costa, J. A. V., \& Wendorff, J.

Table 3. The concentrations of the solutions PHB2 and PHB3 that presented uniform nanofibers $(*)$ and all conditions of the electrospinning process studied.

\begin{tabular}{|c|c|c|c|c|c|c|}
\hline \multicolumn{7}{|c|}{$35 \%$ PHB2 } \\
\hline Experiment & 1 & 2 & $3^{*}$ & 4 & 5 & \\
\hline $\mathrm{EP}(\mathrm{kV})$ & 18.1 & 24.3 & 24.3 & 31.3 & 31.3 & \\
\hline $\operatorname{FR}\left(\mu \mathrm{L} \min ^{-1}\right)$ & 2 & 2 & 2.5 & 2.5 & 3 & \\
\hline $\mathrm{D}_{\mathrm{cc}}(\mathrm{cm})$ & 15 & 15 & 15 & 15 & 15 & \\
\hline $\mathrm{D}_{\mathrm{c}}(\mathrm{mm})$ & 0.45 & 0.45 & 0.45 & 0.45 & 0.45 & \\
\hline \multicolumn{7}{|c|}{$25 \%$ PHB2 + 5\% Sp } \\
\hline Experiment & & 6 & 7 & $8^{*}$ & 9 & \\
\hline $\mathrm{EP}(\mathrm{kV})$ & & 18.1 & 24.1 & 31.2 & 31.2 & \\
\hline $\mathrm{FR}\left(\mu \mathrm{L} \min ^{-1}\right)$ & & 2.5 & 2.5 & 2.5 & 2 & \\
\hline $\mathrm{D}_{\mathrm{cc}}(\mathrm{cm})$ & & 15 & 15 & 15 & 15 & \\
\hline $\mathrm{D}_{\mathrm{c}}(\mathrm{mm})$ & & 0.45 & 0.45 & 0.45 & 0.45 & \\
\hline \multicolumn{7}{|c|}{$30 \%$ PHB3 } \\
\hline Experiment & & 10 & $11^{*}$ & 12 & 13 & \\
\hline $\mathrm{EP}(\mathrm{kV})$ & & 18.1 & 25 & 25 & 31.2 & \\
\hline $\mathrm{FR}\left(\mu \mathrm{L} \min ^{-1}\right)$ & & 2 & 2 & 1 & 1 & \\
\hline $\mathrm{D}_{\mathrm{cc}}(\mathrm{cm})$ & & 15 & 15 & 15 & 15 & \\
\hline $\mathrm{D}_{\mathrm{c}}(\mathrm{mm})$ & & 0.45 & 0.45 & 0.45 & 0.45 & \\
\hline \multicolumn{7}{|c|}{$25 \%$ PHB2 + 5\% Sp } \\
\hline Experiment & & 14 & 15 & 16 & $17^{*}$ & 18 \\
\hline $\mathrm{EP}(\mathrm{kV})$ & & 18.1 & 24.3 & 24.3 & 24.3 & 31.1 \\
\hline $\mathrm{FR}\left(\mu \mathrm{L} \min ^{-1}\right)$ & & 2.5 & 2.5 & 4.8 & 4.8 & 4.8 \\
\hline $\mathrm{D}_{\mathrm{cc}}(\mathrm{cm})$ & & 15 & 15 & 15 & 15 & 15 \\
\hline $\mathrm{D}_{\mathrm{c}}(\mathrm{mm})$ & & 0.45 & 0.45 & 0.45 & 0.90 & 0.90 \\
\hline
\end{tabular}

The different colors indicate where the change occurred between experiments.

Table 4. Characteristics and diameter of the nanofibers formed, and response of viscosity of solutions used for the development of fiber.

\begin{tabular}{ccccc}
\hline Concentration of solution (\%) & Extraction conditions & Fiber characteristics & Diameter (nm) & Viscosity (Pa s) \\
\hline $30 \%$ PHB & PHB1 & Broken fibers containing & - & $0.03 \pm 0.00^{\mathrm{a}}$ \\
& & droplets & $0.05 \pm 0.02^{\mathrm{a}}$ \\
$35 \%$ PHB & PHB2 & Uniform fibers & $1,490 \pm 147.0^{\mathrm{a}}$ & $0.11 \pm 0.05^{\mathrm{a}}$ \\
$25 \%$ PHB $+5 \%$ Spirulina & PHB2 & Uniform Fibers & $1,453 \pm 239.0^{\mathrm{a}}$ & $0.11 \pm 0.01^{\mathrm{a}}$ \\
$30 \%$ PHB & PHB3 & Uniform Fibers & $826 \pm 188.0^{\mathrm{b}}$ & $0.24 \pm 0.04^{\mathrm{b}}$ \\
$25 \%$ PHB $+5 \%$ Spirulina & PHB3 & Uniform Fibers & $1,675 \pm 194.0^{\mathrm{a}}$ & $0.01 \pm 0.00^{\mathrm{a}}$ \\
\hline $30 \%$ PHB & PHB4 & Fibers with droplets & - & \\
\hline
\end{tabular}

Same letters in the same column indicate experiments between which there was no significant difference $(\mathrm{p}>0.05)($ mean \pm standard deviation).

of the nanofibers. With a capillary diameter of $0.84 \mathrm{~mm}$ and PEO concentration of $7 \%$, Son et al., ${ }^{[23]}$ obtained nanofibers with diameters ranging from 360 to $1,960 \mathrm{~nm}$.

There was no significant difference $(p>0.15)$ in viscosity between the solutions that provided the best conditions for electrospinning (Table 4), except for the sample containing $25 \%$ PHB3 and $5 \%$ microalgal biomass, which had nanofibers with a maximum diameter. If the viscosity increases, the diameter of the nanofibers also increases due to the solution's greater resistance to stretching. ${ }^{[8]}$

The viscosities of the solutions ranged from $0.010 \pm 0.002$ to $0.240 \pm 0.040 \mathrm{~Pa} \mathrm{~s}$, with solution with concentrations around $30 \%$ (Table 4 ). Sombatmankhong et al., ${ }^{[15]}$ obtained viscosities from 0.43 to $2.30 \mathrm{~Pa} \mathrm{~s}$, for PHB samples with concentrations between 10 and $16 \%(\mathrm{w} / \mathrm{v})$.

The viscosity can be increased by increasing the concentration of the polymer. This results in polymer chain links within the solution, which makes the jet continuous during electrospinning ${ }^{[8]}$. In this study, the extracted polymers had lower viscosity values when compared with polymers quoted in the literature, but this was offset by the increase of the concentration of the solution, which enabled the development of nanofibers using the electrospinning process.

\section{Conclusions}

The Spirulina LEB 18 microalga had a maximum concentration in PHB1 $(30.1 \pm 2 \%)$. The smallest diameter of nanofibers developed was $826 \pm 188.0 \mathrm{~nm}$, obtained in PHB3 with 30\% solution.

The PHB2 extraction method produced a polymer with a green color and with maximum content of non-PHB materials (34.4\% impurities). This is a desirable outcome for the application of nanofibers in the medical and food fields, because active components in the microalga are preserved and these may assist in cell growth and the development of edible packaging. 


\section{Acknowledgements}

The authors would like to thank CAPES - Coordenação de Aperfeiçoamento de Pessoal de Nível Superior, for the scholarship in Brazil and Germany, and $\mathrm{CNPq}$ - Conselho Nacional de Pesquisa Cientifica e Tecnologica, for their financial support for this study.

\section{References}

1. Jau, M. H., Yew, S. P., Toh, P. S., Chong, A. S., Chu, W. L., Phang, S. M., Najimudin, N., \& Sudesh, K. (2005). Biosynthesis and mobilization of poly(3-hydroxybutyrate) [P(3HB)] by Spirulina platensis. International Journal of Biological Macromolecules, 36(3), 144-151. http://dx.doi.org/10.1016/j. ijbiomac.2005.05.002. PMid:16005060

2. Casarin, S., Agnelli, J., Malmonge, S., \& Rosário, F. (2013). Blendas PHB/copoliésteres biodegradáveis - biodegradação em solo. Polímeros. Ciência e Tecnologia, 23(1), 115-122. http://dx.doi.org/10.1590/S0104-14282013005000003.

3. Choi, J., \& Lee, S. (1999). Factors affecting the economics of polyhydroxyalkanoate production by bacterial fermentation. Applied Microbiology and Biotechnology, 51(1), 13-21. http:// dx.doi.org/10.1007/s002530051357.

4. Hahn, S. K., Chang, Y. K., Kim, B. S., \& Chang, H. N. (1994). Optimization of microbial poly(3-hydroxybutyrate) recover using dispersions of sodium hypochlorite solution and chloroform. Biotechnology and Bioengineering, 44(2), 256-261. http:// dx.doi.org/10.1002/bit.260440215. PMid:18618692

5. Morais, M. G., Stillings, C., Dersch, R., Rudisile, M., Pranke, P., Costa, J. A., \& Wendorff, J. (2010). Preparation of nanofibers containing the microalga Spirulina (Arthrospira). Bioresource Technology, 101(8), 2872-2876. http://dx.doi.org/10.1016/j. biortech.2009.11.059. PMid:20056537

6. Santos, C., Bretas, R., Branciforte, M., \& Canova, T. (2011). Preparação e caracterização de nanofibras de nanocompósitos de poliamida 6,6 e argila montmorilonita. Polímeros: Ciência e Tecnologia, 21(5), 398-408. http://dx.doi.org/10.1590/S010414282011005000068

7. Greiner,A., \& Wendorff, J. H. (2008). Functional self-assembled nanofibers by electrospinning. Advances in Polymer Science, 219, 107-171. http://dx.doi.org/10.1007/12_2008_146.

8. Ramakrishna, S., Fujihara, K., Teo, W. E., Lim, T. C., \& Ma, Z. (2005). An introduction to electrospinning and nanofibers. United States of America: World Scientific Publishing Co. Pte. Ltd. Danvers.

9. Morais, M. G., Reichert, C. C., Dalcanton, F., Durante, A. J., Marins, L. F., \& Costa, J. A. (2008). Isolation and characterization of a new Arthrospira strain. Zeitschrift für Naturforschung C, 63(1-2), 144-150. http://dx.doi.org/10.1515/znc-2008-1-226. PMid:18386504

10. Costa, J. A., Colla, L. M., \& Duarte Filho, P. F. (2004). Improving Spirulina platensis biomass yield using a fed-batch process. Bioresource Technology, 92(3), 237-241. http://dx.doi. org/10.1016/j.biortech.2003.09.013. PMid:14766156

11. Morais, M. G., Radmann, E. M., Andrade, M. R., Teixeira, G. G., Brusch, L. R. F., \& Costa, J. A. V. (2009). Pilot scale semicontinuous production of Spirulina biomass in southern Brazil. Aquaculture, 294(1-2), 60-64. http://dx.doi.org/10.1016/j. aquaculture.2009.05.009.

12. Tsuji, H., \& Ikada, Y. (1996). Blends of aliphatic polyesters. I. Physical properties and morphologies of solution-cast blends from poly(DL-lactide) and poly( $\varepsilon$-caprolactone). Journal of Applied Polymer Science, 60(13), 2367-2375. http://dx.doi
org/10.1002/(SICI)1097-4628(19960627)60:13<2367::AIDAPP8 $>3.0 . C O ; 2-C$.

13. Panda, B., Jain, P., Sharma, L., \& Mallick, N. (2006). Optimization of cultural and nutritional conditions for accumulation of poly$\beta$-hydroxybutyrate in Synechocystis sp. PCC 6803. Bioresource Technology, 97(11), 1296-1301. http://dx.doi.org/10.1016/j. biortech.2005.05.013. PMid:16046119

14. Nishioka, N., Nakai, K., Miyake, M., Asada, Y., \& Taya, M. (2001). Production of poly- $\beta$-hydroxybutyrate by thermophilic cyanobacterium, Synechococcus sp. MA19, under phosphatelimited conditions. Biotechnology Letters, 23(14), 1095-1099. http://dx.doi.org/10.1023/A:1010551614648.

15. Sombatmankhong, K., Suwantong, O., Waleetorncheepsawat, S., \& Supaphol, P. (2006). Electrospun fiber mats of poly(3hydroxybutyrate), poly(3-hydroxybutyrate-co-3-hydroxyvalerate), and their blends. Journal of Polymer Science. Part B, Polymer Physics, 44(19), 2923-2933. http://dx.doi.org/10.1002/ polb.20915.

16. Kim, G. M., Michler, G. H., Henning, S., Radusch, H. J., \& Wutzler, A. (2007). Thermal and spectroscopic characterization of microbial poly(3-hydroxybutyrate) submicrometer fibers prepared by electrospinning. Journal of Applied Polymer Science, 103(3), 1860-1867. http://dx.doi.org/10.1002/app.25348.

17. Matsui, M. S., Muizzuddin, N., Arad, S., \& Marenus, K. (2003). Sulfated polysaccharides from red microalgae have antiinflammatory properties in vitro and in vivo. Applied Biochemistry and Biotechnology, 104(1), 13-22. http://dx.doi. org/10.1385/ABAB:104:1:13. PMid:12495202

18. Borowitzka, M.A. (1995). Microalgae as sources of pharmaceuticals and other biologically active compounds. Journal of Applied Phycology, 7(1), 3-15. http://dx.doi.org/10.1007/BF00003544.

19. Mishima, T., Murata, J., Toyoshima, M., Fujii, H., Nakajima, M., Hayashi, T., Kato, T., \& Saiki, I. (1998). Inhibition of tumor invasion and metastasis by calcium spirulan (Ca-SP), a novel sulfated polysaccharide derived from a blue-green alga, Spirulina platensis. Clinical \& Experimental Metastasis, 16(6), 541-550. http://dx.doi.org/10.1023/A:1006594318633. PMid:9872601

20. Suwantong, O., Waleetorncheepsawat, S., Sanchavanakit, N., Pavasant, P., Cheepsunthorn, P., Bunaprasert, T., \& Supaphol, P. (2007). In vitro biocompatibility of electrospun poly(3-hydroxybutyrate) and poly(3-hydroxybutyrate-co-3hydroxyvalerate) fiber mats. International Journal of Biological Macromolecules, 40(3), 217-223. http://dx.doi.org/10.1016/j. ijbiomac.2006.07.006. PMid:16949148

21. Choi, J. S., Lee, S. W., Jeong, L., Bae, S. H., Min, B. C., Youk, J. H., \& Park, W. H. (2004). Effect of organosoluble salts on the nanofibrous structure of electrospun poly(3-hydroxybutyrateco-3-hydroxyvalerate). International Journal of Biological Macromolecules, 34(4), 249-256. http://dx.doi.org/10.1016/j. ijbiomac.2004.06.001. PMid:15374681

22. Megelski, S., Stephens, J. S., Chase, D. B., \& Rabolt, J. F. (2002). Micro- and nanostructured surface morphology on electrospun polymer fibers. Macromolecules, 35(22), 84568466. http://dx.doi.org/10.1021/ma020444a.

23. Son, W. K., Youk, J. H., Lee, T. S., \& Park, W. P. (2004). The effects of solution properties and polyelectrolyte on electrospinning of ultrafine poly (ethylene oxide) fibers. Polymer, 45(9), 29592966. http://dx.doi.org/10.1016/j.polymer.2004.03.006.

Received: Feb. 14, 2014

Revised: Oct. 06, 2014 Accepted: Nov. 14, 2014 